\title{
Knowledge, attitudes and practices concerning Middle East respiratory syndrome among Umrah and Hajj pilgrims in Samsun, Turkey, 2015
}

MK Sahin ${ }^{1}$, S Aker ${ }^{1}$, E Kaynar Tuncel ${ }^{2}$

1. Samsun Public Health Directorate, Canik Community Health Center, Samsun, Turkey

2. Samsun Public Health Directorate, Bafra Community Health Center, Samsun, Turkey

Correspondence: Mustafa Kürşat Şahin (m.kursatsahin@yahoo.com)

Citation style for this article:

Sahin MK, Aker S, Kaynar Tuncel E. Knowledge, attitudes and practices concerning Middle East respiratory syndrome among Umrah and Hajj pilgrims in Samsun, Turkey, 2015. Euro Surveill. 2015;20(38):pii=30023. DOI: http://dx.doi.org/10.2807/1560-7917.ES.2015.20.38.30023

Article submitted on 14 September 2015 / accepted on 23 September 2015 / published on 24 September 2015

We performed a questionnaire study to determine knowledge, attitudes and practices concerning Middle East respiratory syndrome (MERS) among people intending to participate in the Hajj or Umrah Muslim pilgrimages. Of the 381 respondents aged between 17 and 85 years, $55 \%$ had never heard of MERS, while only one in three knew that it is a respiratory disease. Approximately half were insufficiently informed about protective measures. Prospective pilgrims do not seem prepared to take such precautions.

We performed a survey among people intending to visit the Arabian Peninsula for the Hajj or Umrah pilgrimages and aimed to determine their awareness about Middle East respiratory syndrome (MERS).

Hajj in 2015 will take place from 21 to 25 September. Umrah is a similar pilgrimage that can be undertaken at any time of the year but is likely to be more crowded during the month of Ramadan (18 June to 17 July 2015). In 2015, 55,540 people from Turkey secured the right to perform the Hajj [1]. Because of the ability of infectious diseases to spread rapidly at mass gatherings, the Saudi Ministry of Health $(\mathrm{MoH})$ advises people 65 years and older, pregnant women and children under 12 years and individuals with weak immune systems or chronic diseases to postpone travelling as long as there is the risk of MERS in the area [2]. People wishing to perform the Hajj or Umrah are advised to follow general hygiene measures such as regular hand washing, using disposable materials and using masks [2-4]. Knowledge and application of basic hygiene principles and measures in such an environment is therefore vitally important.

\section{Enrolment in the study}

Residents of Samsun, Turkey, intending to perform the Hajj or the Umrah and applying for immunisation to community health centres before the busiest months for pilgrimages were enrolled during the period from 4 May to 24 July 2015. Samsun is a city with a population of 1.25 million on the north coast of Turkey. It has seven community health centres providing immunisation services for prospective pilgrims (four in the central area and three in outlying districts). Two of these (one in the centre and one outlying) were chosen for this study. In face-to-face interviews, study participants were administered a questionnaire with 16 questions on demographic data and knowledge, attitudes and practices concerning MERS. The participants were informed about the study before the interview. The study was approved by the ethics committee of the Ondokuz Mayıs University Clinical Research Ethics Commission.

\section{Survey participants}

Of the 381 participants, $49 \%$ (185 people) were male and $51 \%$ (196 people) female. Mean ages were $59 \pm 12$ years (range: 17-85). Education above primary school level was recorded for $26 \%$ of the participants (99 people). Sixty-four per cent (244 people) met at least one of the conditions for which the Saudi MoH advises postponement of travel. Chronic diseases, hypertension, diabetes and obesity were significantly more common in women than men ( $p<0.05)$. The influenza vaccination coverage (2014/15 season) was only $7.1 \%$ (27 people). Table 1 shows demographic data and comorbidities for Umrah and Hajj pilgrims who participated in the study.

A quarter $(n=97)$ participants had gone on the Hajj or Umrah at least once previously. The mean number of previous pilgrimages they had made was $1.85 \pm 1.71$.

\section{Knowledge about Middle East respiratory syndrome}

The proportion of participants who had not heard of MERS was $55.6 \%$ (212 people). Awareness of MERS was significantly higher among those who had gone on 
Demographic data and comorbidities in prospective Umrah and Hajj pilgrims, Samsun, Turkey, May-July 2015 (n = 381 )

\begin{tabular}{|c|c|c|c|c|}
\hline & $\begin{array}{l}\text { Women } \\
\mathrm{n}=196\end{array}$ & $\begin{array}{c}\text { Men } \\
n=185\end{array}$ & $\begin{array}{l}\text { Total } \\
\mathrm{n}=381\end{array}$ & $\mathrm{p}$ \\
\hline People older than 65 years & $69(35 \%)$ & $67(36 \%)$ & $136(36 \%)$ & 0.460 \\
\hline Children younger than 12 years & o (o\%) & $\mathrm{o}(0 \%)$ & $\mathrm{o}(0 \%)$ & NA \\
\hline Pregnant women & $1(1 \%)$ & NA & $1(0 \%)$ & NA \\
\hline People with chronic diseases & $117(60 \%)$ & $81(44 \%)$ & $198(52 \%)$ & 0.001 \\
\hline - Hypertension & $88(45 \%)$ & $44(24 \%)$ & $132(35 \%)$ & 0.000 \\
\hline - Diabetes & $51(26 \%)$ & $28(15 \%)$ & $79(21 \%)$ & 0.006 \\
\hline - Respiratory diseases & $14(7 \%)$ & $9(5 \%)$ & $23(6 \%)$ & 0.237 \\
\hline - Heart diseases & $28(14 \%)$ & $21(11 \%)$ & $49(13 \%)$ & 0.242 \\
\hline - Kidney diseases & $7(4 \%)$ & $7(4 \%)$ & $14(4 \%)$ & 0.563 \\
\hline People with cancer & $3(2 \%)$ & $\mathrm{o}(0 \%)$ & $3(1 \%)$ & 0.135 \\
\hline People with weakened immune system or taking immunosuppressive drugs & $1(1 \%)$ & $\mathrm{o}(0 \%)$ & $1(0 \%)$ & 0.514 \\
\hline $\begin{array}{l}\text { At least one condition for which the Saudi MoH recommends postponement } \\
\text { of the Hajj and Umrah }\end{array}$ & $133(68 \%)$ & $111(60 \%)$ & $244(64 \%)$ & 0.068 \\
\hline Obesity & $36(18 \%)$ & $17(9 \%)$ & $53(14 \%)$ & 0.007 \\
\hline People vaccinated against influenza (2014/15 season) & $14(7 \%)$ & $13(7 \%)$ & $27(7 \%)$ & 0.562 \\
\hline
\end{tabular}

MoH: Ministry of Health; NA: not applicable.

A $p$ value of $p<0.05$ was considered significant.

a pilgrimage before (chi-square test: $6.748 ; \mathrm{p}=0.007$ ) and those with university education level (chi-square test: 46,718; p<0.001). Only $34 \%$ of participants (129 people) knew that MERS is a respiratory disease. Of those 169 who were aware of MERS, 60\% (101 people) had heard of it through newspapers or television, $25 \%$ (43 people) from healthcare workers and only $4 \%$ (seven people) from religious officials. Once informed about MERS, almost half of the participants realised the importance of protective measures against MERSCov infections such as hand washing, mask use and avoiding contact with sick people (Table 2). However, only $22.83 \%$ (87 people) knew that antibiotics are ineffective against MERS.

While $76 \%$ of participants (288 people) said they did not intend to take protective measures against MERSCoV infections during the Hajj or Umrah, $21 \%$ (78 people) said they would wear a mask, $14 \%$ (54 people) that they would take care in regard to hand washing and $0.5 \%$ (two people) that they would use hand disinfectants. People with university degrees were significantly more likely to take protective measures than others (chi-square test: $8.093 ; p=0.005$ ).

\section{Discussion}

Although this study cannot be generalised to the entire country, it was the first of its kind in Turkey. According to data from the Ministry of Hajj on 16 July 2015, 5,715,051 Muslims have visited Saudi Arabia to perform Umrah this year [5]. Since its emergence in 2012, the majority of MERS cases have been reported from Saudi Arabia [6]. Cases have also been reported from 25 other countries [7]. According to data from the World
Health Organization on 7 November 2015, there have been 1,495 confirmed cases with 528 deaths to date [8]. The first fatal case from Turkey occurred in 2014 [9].

On the basis of Saudi $\mathrm{MoH}$ recommendations, $64 \%$ of our survey participants should have postponed travelling, but none of them decided to postpone the pilgrimage. That proportion was 18\% in an Australian in 2014 and $50 \%$ in a French study in 2013 [11,12].

More than half of the prospective pilgrims had never heard of MERS. In previous studies, $65 \%$ of French pilgrims and $35 \%$ of Australian pilgrims knew about MERS circulation on the Arabian Peninsula $[11,12]$. Most of those who were aware had learned of it through newspapers or television. Healthcare personnel and religious officials were much rarer sources of information. However, studies have shown that community leaders (e.g. Imams) and healthcare professionals play an important role in health promotion measures $[13,14]$.

The awareness of healthcare personnel and religious officials concerning basic hygiene principles and measures should be increased through effective education and communication strategies. Health education programmes at the entry points to Saudi Arabia have been shown to improve pilgrims' knowledge [15]. Compared with one French (90\%) and one Australian study $(64 \%)$, the level of information concerning protective measures was generally insufficient $[11,16]$. This rate was $42 \%$ in our study, where most pilgrims did not understand the importance of MERS coronavirus infection. Only one in four of our participants intended to 


\section{TABLE 2}

Knowledge of prospective Umrah and Hajj pilgrims about protective measures against Middle East respiratory syndrome and other respiratory diseases, Samsun, Turkey, May-July 2015 ( $\mathrm{n}=381$ )

\begin{tabular}{|l|c|c|}
\hline Protective measures & Number & Percentage \\
\hline Washing hands with soap and water & 218 & 57 \\
\hline Using disposable/single-use materials & 107 & 28 \\
\hline $\begin{array}{l}\text { Not touching the mouth or nose before } \\
\text { hand washing }\end{array}$ & 121 & 32 \\
\hline $\begin{array}{l}\text { Avoiding direct contact with sick } \\
\text { individuals }\end{array}$ & 184 & 48 \\
\hline $\begin{array}{l}\text { Using masks, particularly in crowded } \\
\text { areas }\end{array}$ & 188 & 49 \\
\hline Using hand disinfectants & 145 & 38 \\
\hline
\end{tabular}

take precautions during their pilgrimage. Higher education level appeared to be linked to the intention to take precautions, but attitudes did not always change with knowledge. For example, Iranian pilgrims of old age and with low education level had little knowledge about health subjects, but they had a good health attitude and practice [17].

Attitudes and behaviours of prospective pilgrims can be improved by emphasising the importance of basic hygiene principles and measures through well-structured education programmes, both on MERS and other infectious diseases.

When pilgrims visit health centres for immunisations or mosques for religious rituals, these are occasions for health professionals and imams to inform about MERS.

\section{Conflict of interest}

None declared.

\section{Authors' contributions}

Mustafa Kürşat Şahin: study design, results interpretation, writing the manuscript; Servet Aker: statistics, analysing results, reviewing the manuscript; Ebru Kaynar Tunçel: data collection.
4. Centers for Disease Control and Prevention (CDC). Hajj and Umrah in Saudi Arabia. Atlanta: CDC; Jun 2015. [accessed 7 September, 2015]. Available from: http://wwwnc.cdc.gov/ travel/notices/alert/hajj-umrah-saudi-arabia-2015

5. The Ministry of Hajj, Kingdom of Saudi Arabia. General statistics of the 'Umrah season of 1436 A.H. until 24:00 hours, 28/09/1436 A.H. Total Number of the Mu tamirs: 5,715,051 "General statistics of the “Umrah season of 1436 A.H.". Riyadh: The Ministry of Haji, Kingdom of Saudi Arabia. [Accessed: 7 Sep 2015]. Available from: http://www.haj.gov.sa/en-us/ Pages/default.aspx

6. World Health Organization (WHO). Middle East respiratory syndrome coronavirus (MERS-CoV), Fact sheet no. 401. Geneva: WHO; June 2015. [Accessed: 7 Sep 2015]. Available from: http://www.who.int/mediacentre/factsheets/mers-cov/en/

7. World Health Organization (WHO). Middle East respiratory syndrome coronavirus (MERS-CoV): summary of current situation, literature update and risk assessment. Geneva: WHO; July 2015. [Accessed: 7 Sep 2015]. Available from: http:// apps.who.int/iris/bitstream/10665/179184/2/WHO_MERS_ RA_15.1_eng.pdf

8. World Health Organization (WHO). Middle East respiratory syndrome coronavirus (MERS-CoV). Geneva: WHO. [Accessed: 7 Sep 2015]. Available from: http://www.who.int/emergencies/ mers-cov/en/

9. BayrakdarF, AltaşAB, KorukluoğluG, TopalS. Türkiye'de tespit edilen ilk MERS olgusunun moleküler tanısı ve fi logenetik analizi. [Molecular diagnosis and phylogenetic analysis of the fi rst MERS case in Turkey]. Mikrobiyol Bul. 2015;49(3):414-22. Turkish. DOI: 10.5578/mb.9247 PMID: 26313282

10. Republic of Turkey Presidency of Religious Affairs. Religious Affairs delegation leaves for Saudi Arabia. [Accessed: 7 Sep 2015]. Available from: http://www.diyanet.gov.tr/ $\mathrm{tr} /$ icerik/religious-affairs-delegation-leaves-for-saudiarabia/8157?getEnglish=True

11. GautretP, BenkouitenS, Salaheddinel, BelhouchatK, DraliT, ParolaP, et al. Hajj pilgrims' knowledge about Middle East respiratory syndrome coronavirus, August to September 2013 Euro Surveill. 2013;18(41):pii=20604.DOI: 10.2147/HIV.S42959 PMID: 23785246

12. TashaniM, AlfelaliM, BarasheedO, FatemaFN, AlqahtaniA, RashidH, et al. Australian Haji pilgrims' knowledge about MERS-CoV and other respiratory infections. Virol Sin. 2014;29(5):318-20.DOI: 10.1007/S12250-014-3506-y PMID: 25338843

13. HoggW, DahrougeS, RussellG, TunaM, GeneauR, MuldoonL, et al. Health promotion activity in primary care: performance of models and associated factors. Open Med. 2009;3(3):e165-73. PMID: 21603049

14. Asekun-OlarinmoyelO, Asekun-OlarinmoyeEO, FatiregunA, FawoleOI. Perceptions and activities of religious leaders on the prevention of HIV/AIDS and care of people living with the HIV infection in Ibadan, Nigeria.HIV AIDS (Auckl). 2013;5:121-9.DOI: 10.2147/HIV.S42959 PMID: 23785246

15. TurkestaniA, BalahmarM, IbrahemA, MoqbelE, MemishZA. Using health educators to improve knowledge of healthy behaviour among Hajj 1432 (2011) pilgrims. East Mediterr Health J. 2013;19(Suppl 2):S9-12.PMID: 24673092

16. AlqahtaniAS, WileyKE, WillabyHW, BinDhimNF, TashaniM, HeywoodAE, et al. Australian Hajj pilgrims' knowledge, attitude and perception about Ebola, November 2014 to February 2015. Euro Surveill. 2015;20(12):pii=21072DOI: 10.2147/HIV.S42959 PMID: 23785246

17. Tabatabaei A, Mortazavi SM, Shamspour N, Shushtarizadeh $\mathrm{N}$. Health knowledge, attitude and practice among Iranian pilgrims. Iran Red Crescent Med J. 2015;17(2):e12863. doi: DOI: 10.5812/ircmj.12863. PMID: 25838929.

\section{References}

1. Republic of Turkey Presidency of Religious Affairs. Hac kayıtları 16 Mart'ta başladı. [Hajj registration began on 16 March]. [Accessed: 7 Sep 2015]. Turkish. Available from: http://www.diyanet.gov.tr/tr/icerik/ hac-kayitlari-16-martta-basladi/26639?getEnglish=

2. The Saudi Arabia Ministry of Health $(\mathrm{MoH})$. Health requirements and recommendations for Hajj and Umrah performers and those working in Hajj area 2015. English. Riyadh: The Saudi Arabia MoH. [Accessed: 7 Sep 2015]. Available from: http://www.moh.gov.sa/en/Haij/ HealthGuidelines/HealthGuidelinesDuringHaji/Pages/ HealthRegulations1436.aspx

3. World Health Organization (WHO). World - travel advice on MERS-CoV for pilgrimages. Geneva: WHO; Jun 2014. [accessed 7 September, 2015]. Available from: http://www.who.int/ith/ updates/20140603/en/ 